\title{
Analysis of Precipitate Redistribution in Inconel 617 Using Integrated Electron Backscatter Diffraction and Energy Dispersive Spectroscopy
}

\author{
M. Frary*, S. Schlegel*, S. Hopkins*, E. Young*, J. Cole**, T. Lillo*** \\ * Materials Science and Engineering, 1910 University Drive, Boise, ID 83725-2075 \\ ** Idaho National Laboratory, MFC Building 718, Mailstop 6188, Idaho Falls, ID 83415 \\ *** Idaho National Laboratory, PO Box 1625, Idaho Falls, ID 83415-2218
}

Inconel 617 (IN617), a candidate alloy for applications in the Next Generation Nuclear Plant, derives its oxidation resistance and strength at temperatures above $900^{\circ} \mathrm{C}$ from both solid solution strengthening and the precipitation of carbides [1]. Cr-rich carbides (usually $\mathrm{M}_{23} \mathrm{C}_{6}$ ) reside primarily on grain boundaries, while Mo-rich carbides (usually $\mathrm{M}_{6} \mathrm{C}$ ) tend to be within grains [1-4]. Both intragranular and intergranular carbides play an important role in the creep behavior of the alloy [1]. During creep, intragranular carbides can dissolve and re-precipitate at grain boundaries, especially on boundaries in tension [1]. While the precipitate distribution before and after creep deformation has been investigated, the role of grain boundary character has not been included in the analysis.

IN617 was creep tested at both 900 and $1000^{\circ} \mathrm{C}$ at stresses between 18 and $41 \mathrm{MPa}$. Microstructural characterization using integrated electron backscatter diffraction (EBSD) and energy dispersive spectroscopy (EDS) was done for both gauge (applied stress $>0$ ) and grip (applied stress $\sim 0$ ) sections (see Figure 1). Customized algorithms allowed for analysis of precipitate type, precipitate location, grain boundary character and grain boundary alignment with respect to the stress axis.

During creep, the fraction of precipitates on the boundaries increases in the gauge section $(\sigma>0$, Figure 2). The increase in the grain boundary precipitates is due to an increase in the fraction of Mo-rich carbides on grain boundaries with little change in Cr-rich precipitate locations. The influence grain boundary character (i.e., low-angle, general high-angle, or twin boundary $(\Sigma 3)$ ) has on precipitate location was also investigated. Figure 3 shows that, for most specimens, the majority of precipitates were found on general grain boundaries, despite general boundaries making up less than half of all boundaries. No differences are observed between grip $(\sigma=0)$ and gauge $(\sigma>0)$ sections. Finally, the precipitate distribution was analyzed in terms of the angle between the grain boundary trace and the stress axis $(\theta)$. If precipitates preferentially reside on boundaries in tension, the distribution should be shifted toward $\theta=90^{\circ}$. Figure 4 shows the distribution of precipitates for one specimen in which the $\mathrm{Cr}$-rich precipitates show a strong redistribution in the gauge section. By gathering EBSD and EDS data simultaneously, new insights can be gained on the role of grain boundary character, boundary alignment, and precipitate composition that would not be possible without the integrated data offered by these two methods.

\section{References}

[1] S. Kihara, A. Ohtomo, Y. Saiga, J. B. Newkirk, Metall Mater Trans A 11A (1980) 1019.

[2] F. Jalilian, M. Jahazi, R. A. L. Drew, Mater Sci Eng A 423 (2006) 269.

[3] Y. S. Lim, J. S. Kim, H. P. Kim, H. D. Cho, J Nuc Mater 335 (2004) 108.

[4] H. Liu, M. Gao, D. G. Harlow, R. P. Wei, Scripta Metall Mater 32 (1995) 1807.

[5] This project was supported by a LDRD program at Idaho National Laboratory. 


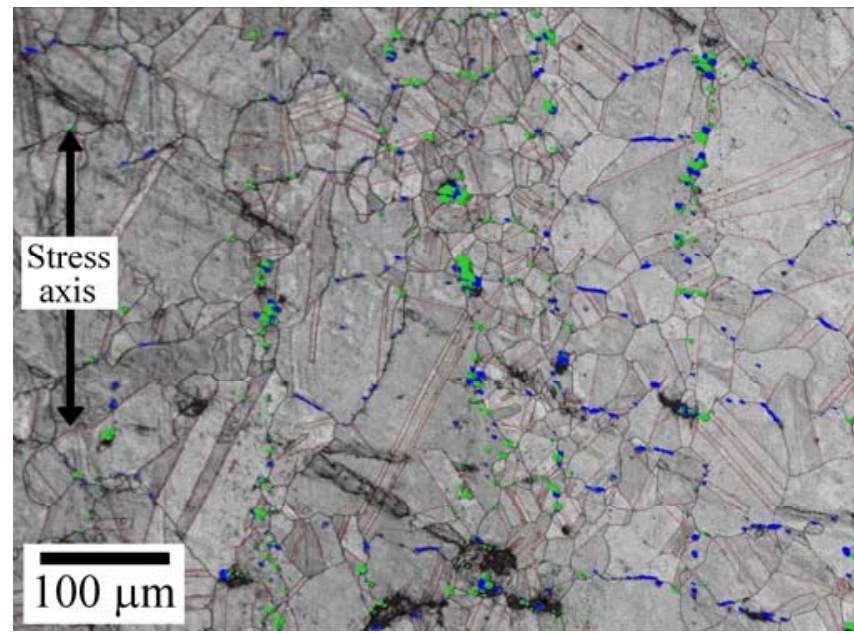

Figure 1: Image quality map showing the distribution of precipitates from the gauge section of the IN617 specimen tested at $1000^{\circ} \mathrm{C}$ and 18.6 $\mathrm{MPa}$. Blue regions are $\mathrm{Cr}$-rich, green regions are Mo-rich, and red lines represent $\Sigma 3$ twin boundaries. The direction of applied stress is vertical in this image.

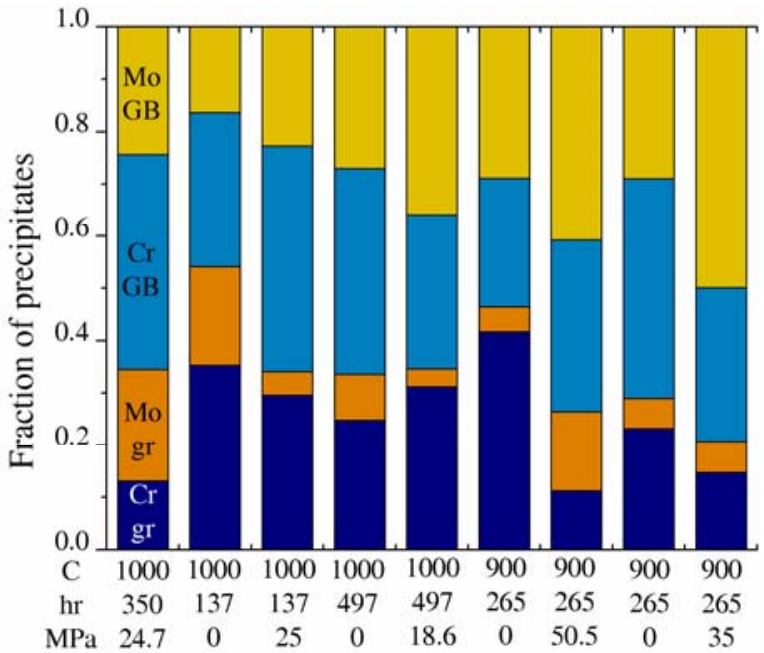

Figure 2: Distribution of precipitates by location (e.g., in grain (gr) or on a grain boundary (GB)) and type (e.g., Cr- or Morich). Each column represents a different test condition (0 MPa indicates grip section).

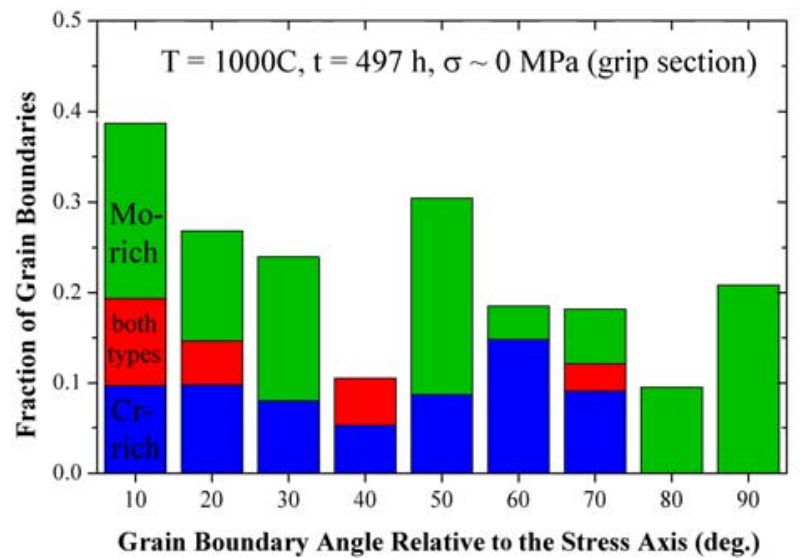

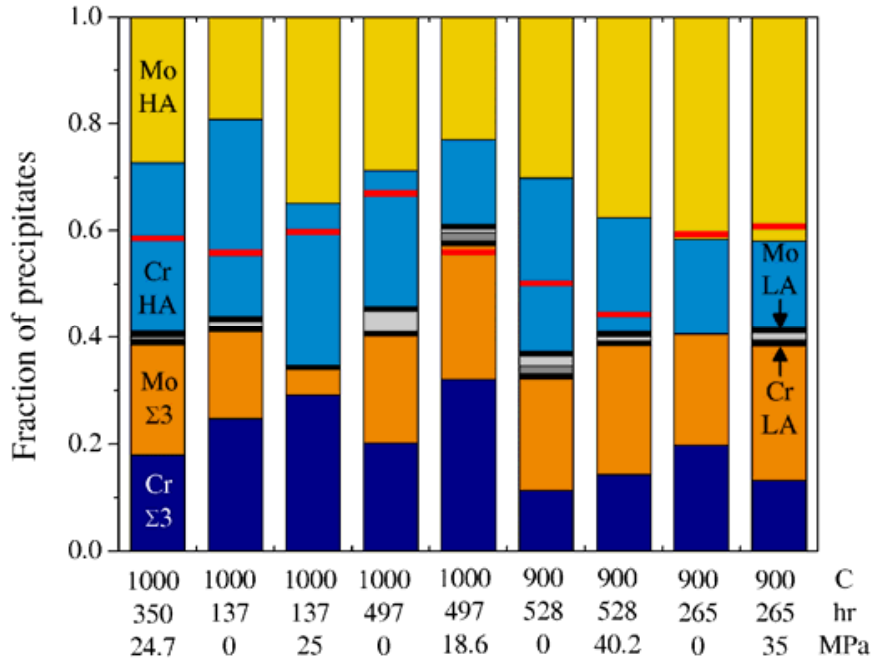

Figure 3: Distribution of grain boundary precipitates by boundary and precipitate type. The red line shows the overall fraction of $\Sigma 3+$ low-angle boundaries in the specimen. Each column represents a different test condition.

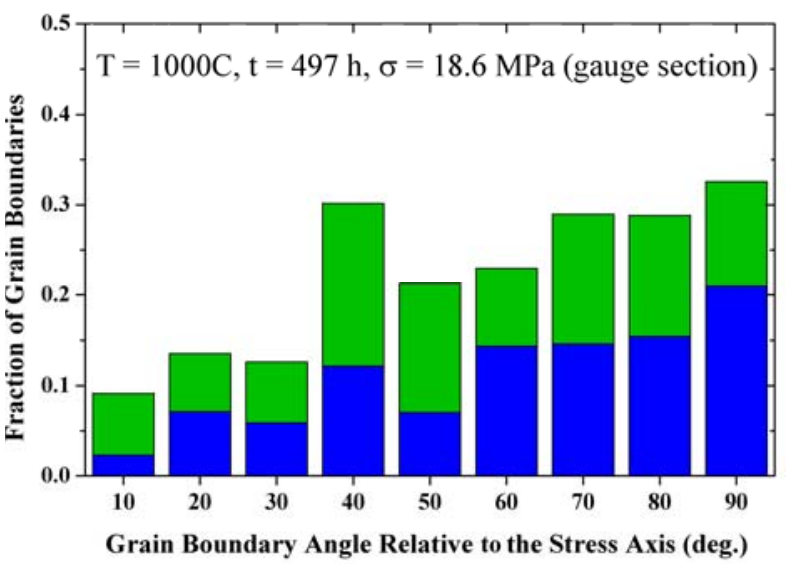

Figure 4: Fraction of grain boundaries populated by precipitates as a function of the angle between the grain boundary trace and applied stress axis for the grip (left, $\sigma \sim 0$ ) and gauge (right, $\sigma>0$ ) for the specimen tested at $1000^{\circ} \mathrm{C}$ and $18.6 \mathrm{MPa}$. 